\title{
Adubação orgânica na produção de pimentão.
}

\author{
Luiz G. Ribeiro; José Carlos Lopes; Sebastião Martins Filho; Silvano S. Ramalho. \\ CAUFES, Caixa Postal 16, 29.500-000 Alegre-ES. E.mail: jcufes@bol.com.br
}

\begin{abstract}
RESUMO
Com o objetivo de avaliar os efeitos da adubação orgânica na produção de pimentão (Capsicum annuum L.), cultivar Nacional AG 506, foram conduzidos dois experimentos: um em casa-de-vegetação e outro a campo na área experimental do Centro Agropecuário da UFES em Alegre (ES), no período de março a outubro de 1994. Em casa-de-vegetação foram avaliados seis níveis de vermicomposto $(0,200,400,600,800$ e $1000 \mathrm{~g}$ por vaso) associados à ausência e presença de adubação química. $\mathrm{O}$ delineamento experimental utilizado foi o inteiramente casualizado com cinco repetições de uma planta por vaso. Após 45 dias foram avaliados o peso da matéria seca da parte aérea e da raiz. No campo, 12 t/ha de vermicomposto (600 g/cova) foram comparados com $20 \mathrm{t} / \mathrm{ha}(1000 \mathrm{~g} /$ cova) de esterco de curral, na ausência e presença de adubação química. Os tratamentos foram distribuídos em blocos ao acaso com quatro repetições de dez plantas por parcela. Por meio de regressão linear, determinou-se que em casa-de-vegetação, a máxima produção de matéria seca da parte aérea foi obtida com a aplicação de $561,9 \mathrm{~g} / \mathrm{vaso}$ de vermicomposto e das raízes com $323,1 \mathrm{~g} /$ vaso, ocorrendo pequenos decréscimos em doses mais elevadas. No experimento de campo a adubação orgânica aumentou a produção em $7,0 \mathrm{t} / \mathrm{ha}$ em relação à testemunha adubada apenas com adubo químico. Não houve diferenças significativas entre as fontes de matéria orgânica (vermicomposto e esterco de curral).
\end{abstract}

Palavras-chave: Capsicum annuum L., esterco de curral, adubo orgânico, vermicomposto.

\begin{abstract}
Organic fertilization in the sweet pepper production.

With the objective of evaluating the effects of the organic fertilization in the production of sweet pepper (Capsicum annuum L.) cultivar Nacional AG 506, two experiments were carried out: one experiment in the greenhouse and other at the Agricultural Center of the Federal University of Espirito Santo (CAUFES) Experimental Station, in the city of Alegre, Brazil, from March to October, 1994. In the greenhouse six levels of earthworm compost were tested $(0,220,400,600,800$ and $1000 \mathrm{~g} /$ pot $)$ associated with the absence or presence of chemical fertilization. The experiments were set up in a complete randomized blocks design, with five replications. Only one plant was used per pot. After 45 days the dry matter production of plant tops and roots was evaluated. In the field $12 \mathrm{t} / \mathrm{ha}$ of earthworm compost $(600 \mathrm{~g}$ per pot) were compared with $20 \mathrm{t} / \mathrm{ha}$ (1000 g per pot) of cattle manure, in the absence and presence of chemical fertilization. The experiment was laid out in a complete randomized block design, with four replications of ten plants per plot. In greenhouse the maximum top dry weight was obtained with 561.9 $\mathrm{g} /$ pot of earthworm compost and with $323.1 \mathrm{~g} /$ pot for maximum root dry weight. Decrease in dry weight production was observed when higher amounts of earthworm compost were used. In a field experiment, sweet pepper production with organic fertilization was 7.0 t/ha higher when compared to chemical fertilization. There was no significant difference among sources of organic fertilization (earthworm compost and cattle manure),
\end{abstract}

Keywords: Capsicum annuum L., cattle manure, organic fertilizer, earthworm compost.

(Aceito para publicação em 18 de maio de 2.000)

$\mathrm{O}^{2}$ pimentão (Capsicum annuum L.) uma das dez hortaliças de maior importância econômica no mercado brasileiro. É uma planta bastante exigente nas características químicas e físicas do solo, com boa resposta à adubação orgânica, sendo que as maiores produtividades são obtidas através da combinação de adubos orgânicos e minerais (Horino et al., 1986; Souza, et al., 1991). A aplicação de adubos e corretivos na cultura do pimentão é uma prática agrícola onerosa que representa em média $23,4 \%$ do custo total de produção. A utilização de estercos e outros compostos orgânicos apresenta-se como alternativa promissora capaz de reduzir as quantidades de fertilizantes químicos a serem aplicados (Almeida et al., 1982; Silva Júnior, 1986; Munis et al.,1992).
O vermicomposto é um fertilizante orgânico produzido por decomposição aeróbica controlada que envolve inicialmente fungos e bactérias, e na fase final as minhocas que aceleram a decomposição. O produto é um composto de qualidade, rico em nutrientes, cuja utilização, além de restaurar o ciclo biológico do solo, reduz as infestações de pragas, doenças e uso de agrotóxicos, conferindo maior resistência e melhor desenvolvimento às plantas (Harris, 1990 citado por Ricci et al., 1994; Longo, 1992).

O trabalho teve como objetivo estudar os efeitos da aplicação de esterco de curral e vermicomposto como fonte de adubação orgânica na produção de pimentão.

\section{MATERIAL E MÉTODOS}

Este estudo foi conduzido em casade-vegetação e a campo na área experimental de Rive, pertencente ao Centro Agropecuário da Universidade Federal do Espírito Santo (CAUFES), no período de março a outubro de 1994.

O primeiro experimento foi conduzido em casa de vegetação coberta com tela sombrite $(40 \%)$, onde foram testados seis doses de vermicomposto $(0$, $200,400,600,800$ e $1000 \mathrm{~g} /$ vaso) associados à ausência e à presença de adubação química utilizando-se $2,0 \mathrm{~g}$ de $\mathrm{N}$ como sulfato de amônia; $7,0 \mathrm{~g}$ de $\mathrm{P}_{2} \mathrm{O}_{5}$ como superfosfato simples e $4,0 \mathrm{~g}$ de $\mathrm{K}_{2} \mathrm{O}$ como cloreto de potássio por vaso, 


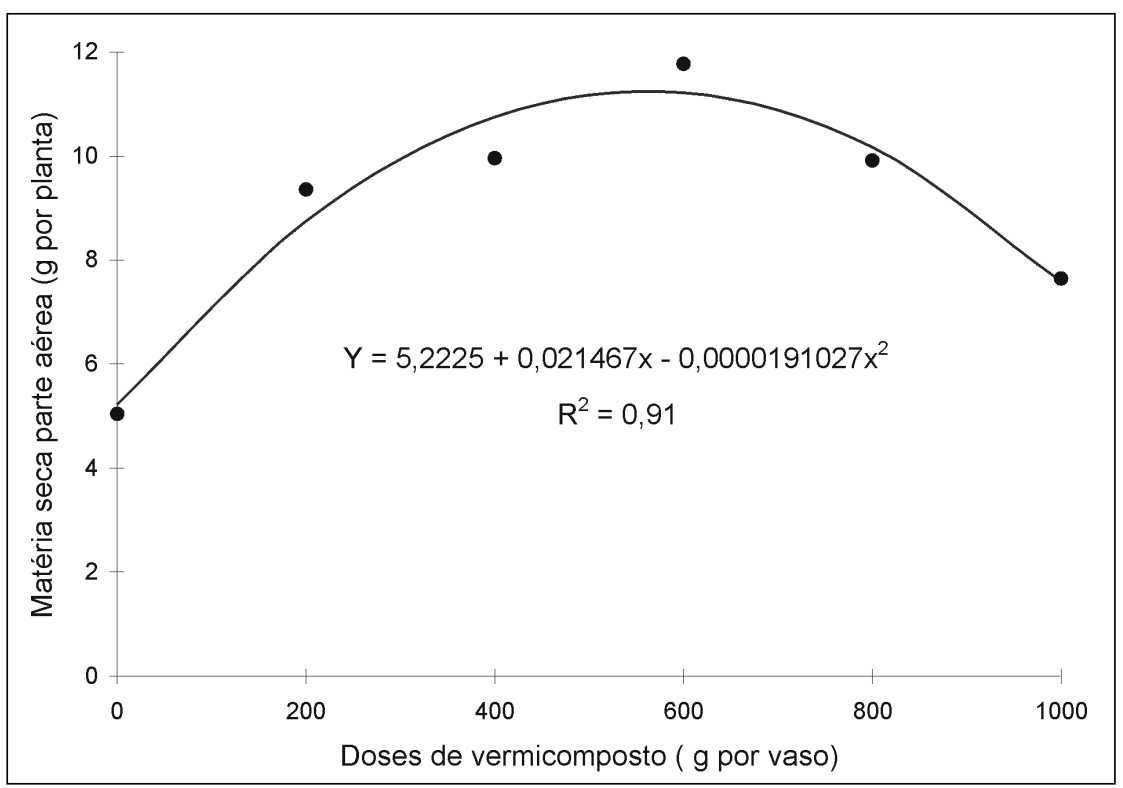

Figura 1. Efeito das doses de vermicomposto na presença e ausência de adubação química sobre a produção de matéria seca da parte aérea de pimentão produzido em casa de vegetação. Alegre (ES), CAUFES, 1994.

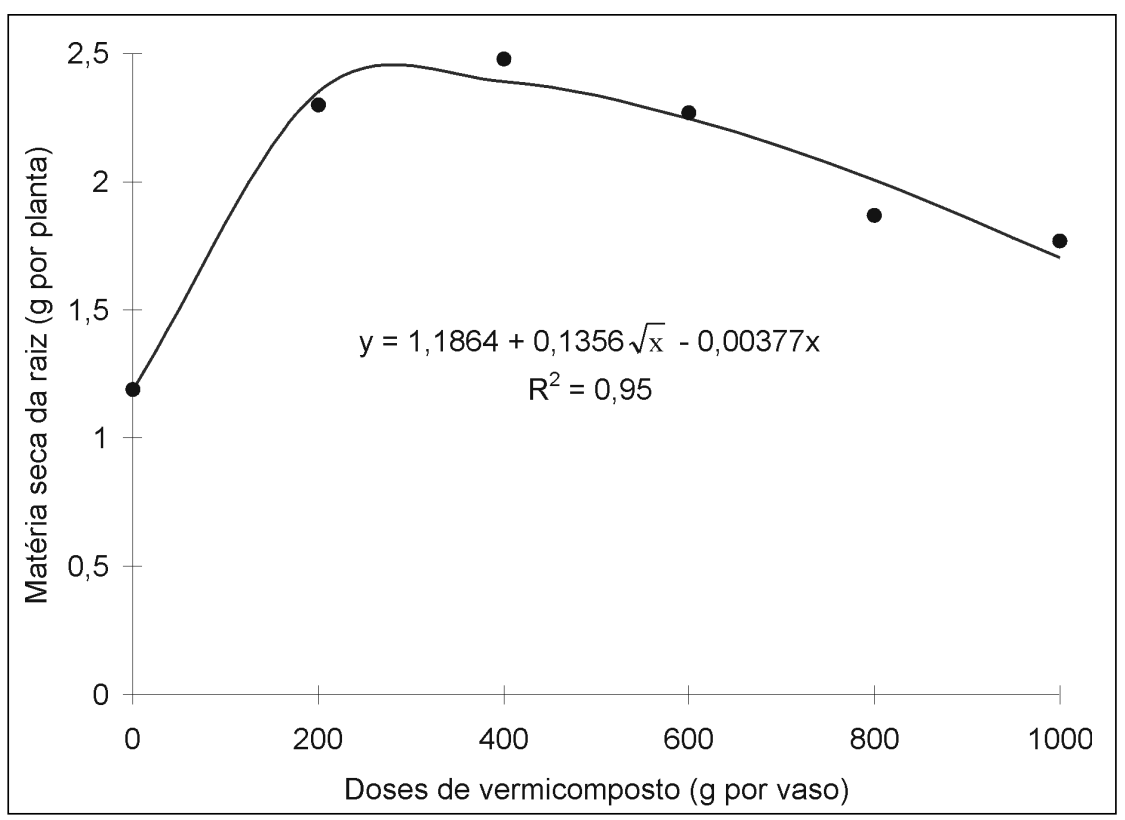

Figura 2. Efeito das doses de vermicomposto na presença e ausência de adubação química sobre a produção de matéria seca da raiz de pimentão produzido em casa de vegetação. Alegre (ES), CAUFES, 1994.

misturados uniformemente ao solo. Utilizou-se como substrato um solo tipo latossolo vermelho-amarelo, textura argilosa, cuja análise química revelou as seguintes caraterísticas: $\mathrm{pH}: 5,4 ; \mathrm{Al}$ trocável: $0,0 \mathrm{cmol} \mathrm{dm}^{-3}$; Ca: $0,8 \mathrm{cmol}$ $\mathrm{dm}^{3}$; Mg: $0,7 \mathrm{cmol} \mathrm{dm}^{-3}$; P: $8 \mathrm{mg} \mathrm{kg}^{-1}$; $\mathrm{K}: 27 \mathrm{mg} \mathrm{kg}^{-1}$ e MO: $15,5 \mathrm{~g} \mathrm{~kg}^{-1}$. O delineamento experimental utilizado foi inteiramente casualizado com 5 repetições em um solo tipo podzólico vermelho escuro, cuja análise indicou a seguinte composição: $\mathrm{pH}$ : 6,30; Al trocável: 0,00 $\mathrm{cmol}_{\mathrm{c}} \mathrm{dm}^{-3}$; $\mathrm{Ca}: 3,10 \mathrm{cmol}_{\mathrm{c}} \mathrm{dm}^{-3} ; \mathrm{Mg}$ : $1,30 \mathrm{cmol}_{\mathrm{c}} \mathrm{dm}^{-3}$; P: $8,00 \mathrm{mg} \mathrm{kg}^{-1}$; K: 0,75 $\mathrm{cmol}_{\mathrm{c}} \mathrm{dm}^{-3}$; e MO: 42,60 $\mathrm{g} \mathrm{kg}^{-1}$. Os tratamentos consistiram de $12 \mathrm{t} / \mathrm{ha}$ de vermicomposto (600 g/cova); esterco de curral na dose de $20 \mathrm{t} / \mathrm{ha}$ (1000 g/cova), na ausência e na presença de adubação química utilizando-se $3,5 \mathrm{~g}$ de $\mathrm{N}$ como uréia; $9,8 \mathrm{~g}$ de $\mathrm{P}_{2} \mathrm{O}_{5}$ como superfosfato simples e 4,6 g de $\mathrm{K}_{2} \mathrm{O}$ como cloreto de potássio por cova. As adubações de cobertura foram realizadas aos 15,30 e 45 dias após o transplantio, utilizando-se $5,7 \mathrm{~g}$ de $\mathrm{Ne} 1,2 \mathrm{~g}$ de $\mathrm{K}_{2} \mathrm{O}$ por planta. $\mathrm{O}$ delineamento experimental utilizado a campo foi o de blocos ao acaso com quatro repetições. Cada parcela constou de 10 plantas em uma única fileira, no espaçamento de $1,00 \mathrm{~m}$ X 0,50 m.

As mudas foram produzidas em copos de papel e transplantadas para o campo 30 dias após a semeadura. Após 90 dias foram colhidas 15 folhas do terço médio das plantas por parcela para análise dos conteúdos de nitrogênio, fósforo, potássio, cálcio e magnésio e os frutos a cada sete dias para análise das variáveis peso, comprimento médio e produção comercial.

O vermicomposto utilizado nos trabalhos em casa-de-vegetação e a campo apresentava as seguintes características: $\mathrm{pH}: 7,70 ; \mathrm{N}: 1,72 \%$; Ca: $2,65 \%$; Mg: 0,34\%; P: 1,30\%; K: 0,85\% е MO: $188,00 \mathrm{~g} \mathrm{~kg}^{-1}$.

Os dados obtidos em casa de vegetação foram submetidos à analise de regressão, selecionando o modelo significativo de maior coeficiente de correlação e os de campo à análise de variância, e as médias comparadas pelo teste de Tukey ao nível de 5\% de probabilidade.

\section{RESULTADOS E DISCUSSÃO}

Em casa de vegetação, não houve interação entre doses de vermicomposto e adubação química. Observou-se um acréscimo na produção de matéria seca da parte aérea da plantas (Figura 1), Y $=5,22+2,15 \cdot 10^{-2} \mathrm{X}-1,91 \cdot 10^{-5} \mathrm{X}^{2} ; \mathrm{R}^{2}=$ 0,91 , à medida que se aumentou a dose de vermicomposto em mistura com o substrato. Nos tratamentos que recebe- 
ram adubação orgânica na presença e ausência de adubação química, a máxima produção de matéria seca da parte aérea $(11,25 \mathrm{~g} /$ planta) foi obtida com dose de 561,96 g/vaso de vermicomposto, ocorrendo pequenos decréscimos nas doses mais elevadas.

A maior produção de matéria seca da raiz (2,4 g/planta), na presença e ausência de adubação química, foi obtida com a dosagem de 323,1 g/vaso de vermicomposto (Figura 2), Y $=1,1864$

$+0,1356 \sqrt{X}-0,00377 \mathrm{X} ; \mathrm{R}^{2}=0,95$, ocorrendo leve queda na produção em doses mais elevadas, analogamente ao padrão de comportamento ocorrido para matéria seca da parte aérea.

A produção média de matéria seca da parte aérea e da raiz nos tratamentos que receberam adubação química (14,1 g e 2,6 g), diferiram significativamente dos dados de produção na ausência do adubo químico $(3,80 \mathrm{~g}$ e $1,36 \mathrm{~g}$ ), o que pode ser atribuído à boa eficiência da planta de pimentão na absorção de nutrientes colocados à sua disposição no plantio e em cobertura.

No experimento de campo, as análises estatísticas não revelaram interações significativas entre as fontes de variação para as características avaliadas. Os tratamentos feitos com adubação orgânica e adubação orgânica + química (Tabela 1) determinaram aumento significativo no peso médio dos frutos, com destaque para o tratamento feito com vermicomposto na presença de adubação química, onde o peso médio de frutos foi maior (76,6 $\mathrm{g} /$ fruto), diferindo estatisticamente da testemunha sem adubação e com adubação química. Em média, os tratamentos que receberam adubação orgânica proporcionaram um ganho adicional de $6,5 \mathrm{~g}$ /fruto em relação à testemunha que só recebeu adubação química.

Os tratamentos feitos com adubação orgânica utilizando esterco de curral, esterco de curral + adubação química, vermicomposto e vermicomposto + adubação química, embora não tenham aumentado significativamente o comprimento médio dos frutos, resultaram em aumento significativo no peso dos frutos, o que pode ser atribuído ao maior diâmetro ou espessura do fruto, ocor-

Tabela 1. Valores médios de peso de frutos, comprimento médio de frutos e produção de pimentão obtidos em condições de campo, em função da adubação orgânica associada à ausência e presença de adubo químico. Alegre (ES), CAUFES, 1994.

\begin{tabular}{lccc}
\hline \multicolumn{1}{c}{ Tratamentos } & $\begin{array}{c}\text { Peso médio } \\
\text { de frutos } \mathbf{( g )}\end{array}$ & $\begin{array}{c}\text { Comprimento } \\
\text { médio de } \\
\text { frutos } \mathbf{( c m )}\end{array}$ & $\begin{array}{c}\text { Produção } \\
\text { (t ha-1) }\end{array}$ \\
\hline Sem adubação & $65,5 \mathrm{c}$ & $8,9 \mathrm{a}$ & $13,6 \mathrm{ab}$ \\
Adubação química & $67,8 \mathrm{bc}$ & $9,0 \mathrm{a}$ & $13,1 \mathrm{~b}$ \\
Esterco de curral & $73,6 \mathrm{ab}$ & $9,1 \mathrm{a}$ & $17,2 \mathrm{ab}$ \\
Esterco + química & $74,1 \mathrm{ab}$ & $9,4 \mathrm{a}$ & $20,1 \mathrm{a}$ \\
Vermicomposto & $72,9 \mathrm{abc}$ & $9,3 \mathrm{a}$ & $16,0 \mathrm{ab}$ \\
Verm. + A. química & $76,6 \mathrm{a}$ & $9,2 \mathrm{a}$ & $20,1 \mathrm{a}$ \\
\hline CV (\%) & 4,3 & 4,1 & 14,1 \\
\hline
\end{tabular}

*/As médias seguidas de mesma letra minúscula, na coluna, não diferem significativamente, a $5 \%$ de probabilidade, pelo teste de Tukey.

rendo uma tendência de maior ganho de produtividade. Esses resultados indicam que as fontes de matéria orgânica utilizadas no experimento de campo, vermicomposto e esterco de curral, não apresentaram diferenças significativas entre si para todas as características analisadas.

Em média, a aplicação de adubo orgânico na ausência do adubo químico proporcionou um ganho adicional de 3,5 t/ha em relação à testemunha química, enquanto na presença de adubo químico este ganho adicional foi de 7,0 t/ha. Nestes tratamentos, a diferença de produção obtida pode ser atribuída à melhoria nas características físicas e químicas do solo pela utilização do vermicomposto e esterco de curral que além da estrutura do solo e aumento na CTC, proporcionaram maior disponibilidade de nutrientes para as plantas (Gras, 1987; Trehan \& Wild, 1993). Esses resultados corroboram a afirmação de Haag et al. (1970), de que a produção de pimentão está altamente associada com os teores de nutrientes nas folhas. As análises foliares revelaram limites mínimos de 31,2; 4,1; 25,5; 24,3 e 7,2 gramas por quilo de matéria seca para nitrogênio, fósforo, potássio, cálcio e magnésio, respectivamente. Portanto, para todos os tratamentos, os valores obtidos estão acima dos teores de macronutrientes considerados como adequados na análise foliar das hortaliças proposto por Magalhães (1988). Os valores considerados elevados, inclusive nas plantas controle, podem estar associados à alta fertilidade do solo amostrado por se tratar de áreas de produção vegetal com acidez corrigida e elevada porcentagem de matéria orgânica. Haag et al. (1970) também sugerem que para uma produção de frutos de boa qualidade há necessidade de que os teores de nitrogênio, fósforo, potássio, cálcio, magnésio e enxofre em gramas por quilo encontrados na matéria seca da parte vegetativa da planta sejam de 27,$9 ; 3,0 ; 35,0 ; 18,4 ; 2,3$ e 4,5, respectivamente.

Com base nos resultados apresentados e condições em que foi realizado o trabalho, conclui-se que a matéria orgânica foi eficiente na produção de pimentão aumentando a produtividade. Não existe diferenças entre o uso de esterco de curral e vermicomposto para as características de produção analisadas. $\mathrm{O}$ uso de matéria orgânica dispensa a adição de fertilizantes químicos.

\section{LITERATURA CITADA}

ALMEIDA, D.L.; MAZUR, N.P.; PEREIRA, N.C. Efeitos de composto de resíduos urbanos em cultura do pimentão no município de Teresópolis-RJ. In: CONGRESSO BRASILEIRO DE OLERICULTURA, 22, Vitória. Resumos. Vitória: SOB/SEAG-ES, 1982 p. 322.

HAAG, H.P.; HOMA, P.; KIMOTO, T. Nutrição mineral de hortaliças. V - Absorção de nutrientes pela cultura do pimentão. $O$ solo, São Paulo, v. 62, n. 2, p. 7-11. 1970.

HORINO, Y.; LIMA, J.A.; CORDEIRO, C.M.T.; ROSSI, P.E. Influência da matéria orgânica e níveis de fósforo na produção de pimentão. Horticultura Brasileira, Brasília, v. 4, n. 1, p. 58. 1986. 
GRAS, R. Proprietés physiques des substrats. In: INRA. Les cultures hors sol. Paris, 1987. p. 80-126.

LONGO, A.D. Minhoca - de fertilizadora do solo à fonte alimentar. São Paulo: Ícone, 1992. 79 p.

MAGALHÃES, J.R. Diagnose de desordens nutricionais em hortaliças. Brasília, EMBRAPA, DPV, 1988, 64 p. il.

MUNIZ, J.O.L.; SILVA, L.A.; ALMEIDA, J.J.L. Efeito das adubações orgânica e orgânica-química em pepino no litoral do Ceará. Horticultura Brasileira, Brasília, v. 10, n. 1, p. 38-39. 1992.
PRIMAVESI, A.M. Manejo Ecológico do Solo: a Agricultura em Regiões Tropicais. 8.ed., São Paulo: Nobel, 1985, 541 p.

SILVA JÚNIOR, A.A. Adubação mineral e orgânica em repolho. Horticultura Brasileira, Brasília, v. 4, n. 2, p.19-21. 1986.

SOUZA, W.P.; BRUNO, G.B. Efeito da adubação organomineral sobre a produção de pimentão. Horticultura Brasileira, Brasília, v. 9, n. 1, p. 60. 1991.

RICCI, M.S.F.; CASALI, V.W.D.; CARDOSO, A.A.; RUIZ, H. A. Produção de alface adubada com composto orgânico. Horticultura Brasileira, Brasília, v. 12, n. 1, p. 56-58. 1994.
TREHAN, S.P.; WILD, A. Effects of an organic manure on the transformations of ammonium nitrogen in planted and umplanted soil. Plant and soil, v. 151, p. 287-294. 1993.

VIDIGAL, S.M.; SEDIYAMA, M.A.N.; GARCIA, N.P.C.; MATOS, A.T. Produção de alface cultivada com diferentes compostos orgânicos e dejetos suínos. Horticultura Brasileira, Brasília, v. 415, n. 1, p. 35-39. 1997. 